\title{
Reduction of the Stress Concentration Factor of Prismatic Specimens Through the Use of Topological Optimization
}

\author{
Raycho Raychev \\ Faculty of Mechanical Engineering \\ Technical University of Sofia, Branch Plovdiv \\ Plovdiv, Bulgaria \\ rpraichev@tu-plovdiv.bg
}

\author{
Ivanka Delova \\ Faculty of Mechanical Engineering \\ Technical University of Sofia, Branch Plovdiv \\ Plovdiv, Bulgaria \\ prosto_vanq89@abv.bg
}

\begin{abstract}
The article presents studies related to the reduction of stress concentration acting on prismatic specimen subject to axial loading. Using ANSYS software, a topological optimization was performed which aims to reduce the stresses in the endangered areas. The aim of identification of the geometric parameters accomplished after the completion of topological optimization of the objective function is to minimize the stresses in the engaged areas. An analysis performed were to show the influence of stresses acting on the fatigue limit during different cycles. The results of the study were present in a graphical form.
\end{abstract}

Keywords - stress concentration, ANSYS, axial loading, topological optimization.

\section{INTRODUCTION}

This article presents the results of simulations related to the study of stress concentration in prismatic specimens subjected to axial loading.

A number of scientific papers are devoted to research related to the reduction of stresses in local areas by specific details.

Studies related to the reduction of the stress concentration coefficient in rectangular plates are presented in [1]. Plates with a main central notch in two variants were studied: with the presence of additional notches and without them. The results of the experiment show that the presence of additional notches located at a certain distance from the main notch reduces the stress concentration factor by more than $30 \%$.

Examination of a rectangular plate with the presence of a central notch with a square and triangular shape is presented in [2]. The main purpose is to determine the influence of the various parameters of the specific notches, such as the direction of loading and the orientation of the notches, on the stress distribution and SCF in the perforated plates. The study was performed using specialized ANSYS software. The presented results show that the stress concentration factor can be significantly reduced by using a suitable shape and orientation of the central notches.

Reducing the concentration of stresses through the introduction of a new approach is the subject of [3]. This approach is called Reliever Topological Material Elimination (RTME) and involves the removal of material from test specimens. Topological optimization was used to determine the best areas for material removal. To evaluate the effectiveness of the method, an analysis was performed using specialized software. The obtained results show that the RTME approach reduces the stress concentration by $35.5 \%$ and reduces by about $28 \%$ the initial volume of the studied specimen.

An approach for optimizing the shape of the studied specimens is also presented in [4]. It is based on the Level Set Method and the X-FEM method, compiling between shape optimization and topological optimization. The application of the described approach is illustrated by minimizing the stress concentration in a $2 \mathrm{D}$ mechanical structure.

Minimization of the peak tangential stresses around the notch boundary in a uniaxially or biaxially loaded plate is the main goal in [5]. The optimization method used is based on iterative finite element analysis. The Fortran 90 software was used to perform the optimization task. The efficiency of the proposed multi-peak method was 
demonstrated by 2D and 3D numerical examples, some of which include significant geometric constraints.

A significant number of studies of perforated plates with optimized notch shapes have been performed. Analysis of the results shows that the optimal notch shapes lead to a significant reduction in peak stress for all regions around the notch boundary, compared to typical suboptimal round notches.

Reducing the stress concentration by obtaining shoulder fillet with a variable radius is described in [6]. Two approaches are used: The first approach is called the local curvature method (LCM). It is based on the results of stress analysis in stepped test specimens with a constant radius, with a change in the local curvature as a function of the local surface tension. The second approach involves the use of specialized modeFrontier software to perform a systematic search for possible design solutions of shoulder fillets radius, using multiple finite element models.

The main purpose of this article is to reduce the stress concentration in prismatic specimens subjected to axial loading with the help of specialized software.

\section{MATERIALS AND METHODS}

The objects of study are a rectangular plate with symmetrically arranged semicircular notches and stepped flat specimen with shoulder fillets. The samples are subjected to axial loading performed with the help of specialized ANSYS software.

To reduce the stress concentrations, the built-in ANSYS module "Topology Optimization" was used, which simulates the removal of material from the studied objects. In this way, along with reducing the mass of the samples, the stresses in the endangered areas are reduced.

The objects of the study are presented in schematic form in Fig. 1.
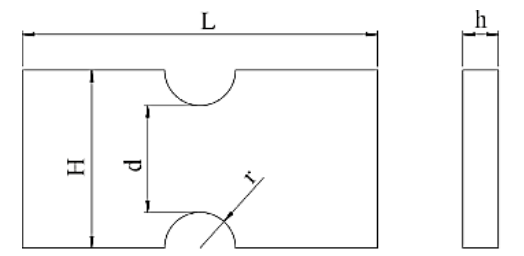

(a)

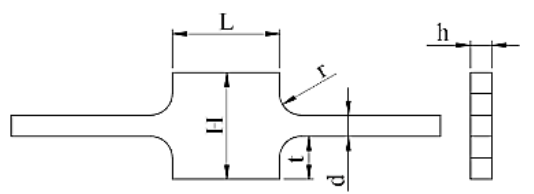

(b)

Fig. 1. Objects of study: (a) Rectangular plate with symmetrically arranged semicircular notches, (b) Stepped flat specimen with shoulder fillets.

The geometric dimensions of the tested specimens are given in Table I and Table II.
TABLE I.

\begin{tabular}{|c|c|c|c|c|}
\hline \multicolumn{5}{|c|}{$\begin{array}{c}\text { Geometric dimensions of a plate with symmetrical } \\
\text { semicircular notches. }\end{array}$} \\
\hline $\mathrm{H}, \mathrm{mm}$ & $L, m m$ & $h, m m$ & $d, m m$ & $r, m m$ \\
\hline \multirow{4}{*}{50} & \multirow{4}{*}{100} & \multirow{4}{*}{10} & 40 & 5 \\
\hline & & & 30 & 10 \\
\hline & & & 20 & 15 \\
\hline & & & 10 & 20 \\
\hline
\end{tabular}

TABLE II.

\begin{tabular}{|c|c|c|c|c|c|}
\hline \multicolumn{6}{|c|}{$\begin{array}{l}\text { Geometric dimensions of stepped flat specimen with } \\
\text { shoulder fillets. }\end{array}$} \\
\hline $\mathrm{H}, \mathrm{mm}$ & $\mathbf{L}, \mathbf{m m}$ & $h, m m$ & $t, \mathrm{~mm}$ & $d, m m$ & $r, \mathbf{m m}$ \\
\hline \multirow{4}{*}{50} & \multirow{4}{*}{50} & \multirow{4}{*}{10} & \multirow{4}{*}{20} & \multirow{4}{*}{10} & 1,5 \\
\hline & & & & & 2,5 \\
\hline & & & & & 6 \\
\hline & & & & & 10 \\
\hline
\end{tabular}

With the help of the static load module in ANSYS, an axial force was applied to the tested specimens, as a result of which the maximum values of the stresses in the endangered areas were obtained. The results of the static analysis were used to perform the software topological optimization.

In order to identify the geometrical parameters of the taken material after the optimization, the OptiSLang additional module was used, and the minimization of the stresses in the endangered areas was indicated as a target function.

\section{RESULTS AND DISCUSSION}

Table III and Table IV present the results of the static analysis at different ratios of the geometric parameters in the models.

TABLE III.

\begin{tabular}{|l|c|c|c|c|c|}
\hline \multicolumn{5}{|c|}{ Plate with symmetrical semicircular notches. } \\
\hline \multirow{2}{*}{$\boldsymbol{d}, \boldsymbol{m m}$} & Axial Force & $\boldsymbol{\sigma} \max$ & $\boldsymbol{\sigma}$ & Ktg-sim & Ktg-theory \\
\cline { 2 - 6 } & $\boldsymbol{P}, \boldsymbol{N}$ & $\boldsymbol{M P a}$ & $\boldsymbol{M P a}$ & - & - \\
\hline 40 & & 315,46 & 100 & 3,155 & 3,08 \\
\hline \multirow{3}{*}{50} & \multirow{3}{*}{5000} & 318,29 & 100 & 3,183 & 3,1 \\
\cline { 4 - 6 } 20 & & 358,38 & 100 & 3,584 & 3,52 \\
\hline 10 & & 581,93 & 100 & 5,819 & 5,78 \\
\hline
\end{tabular}

TABLE IV.

\begin{tabular}{|c|c|c|c|c|c|}
\hline \multicolumn{6}{|c|}{ Stepped flat specimen with shoulder fillets. } \\
\hline & Axial Force & $\sigma \max$ & $\sigma$ nom & Kt-sim & Kt-theory \\
\hline$r, m$ & $P, N$ & MPa & MPa & - & - \\
\hline 1,5 & \multirow{4}{*}{10000} & 220,4 & \multirow{4}{*}{100} & 2,204 & 2,386 \\
\hline 2,5 & & 183,8 & & 1,838 & 2,038 \\
\hline 6 & & 144,3 & & 1,443 & 1,562 \\
\hline 10 & & 138,2 & & 1,382 & 1,35 \\
\hline
\end{tabular}

Comparisons between the theoretical coefficients of stress concentration and those obtained with the simulation 
Environment. Technology. Resources. Rezekne, Latvia Proceedings of the $13^{\text {th }}$ International Scientific and Practical Conference. Volume 3, 296-299

data for the two specimens are presented in a graphical form in Fig. 2 and Fig. 3.

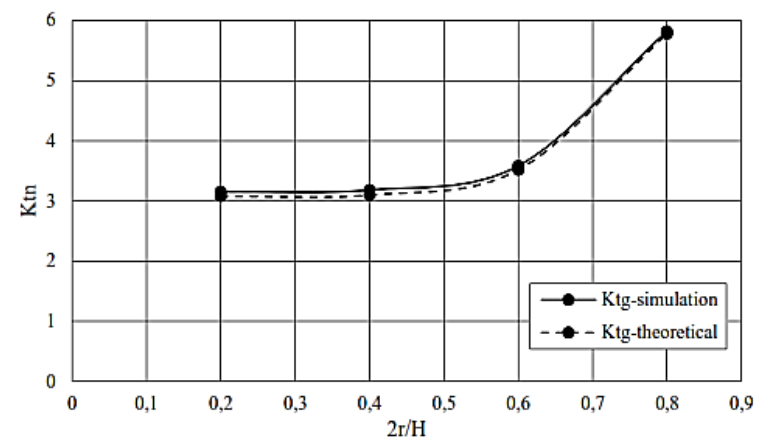

Fig. 2. Comparisons between stress concentration coefficients at plate with symmetrical semicircular notches.

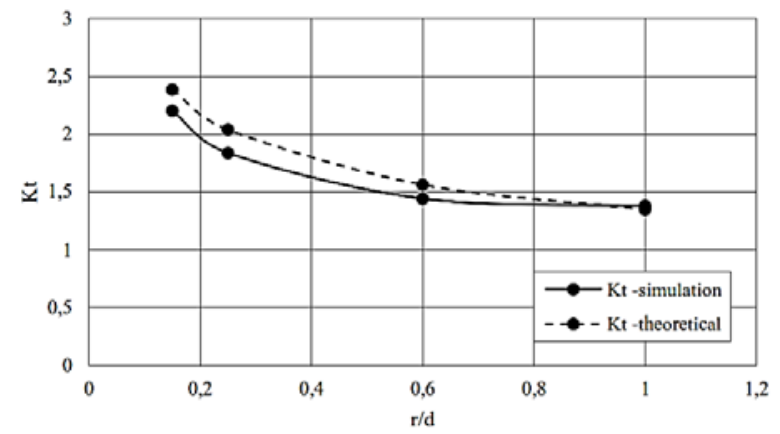

Fig. 3. Comparisons between stress concentration coefficients at Stepped flat specimen with shoulder fillets.

The theoretical coefficients are calculated according to (1) and (2) which are presented in the specialized literature [7].

For the rectangular plate with semicircular notches:

$$
K_{t n}=\frac{\sigma_{\max }}{\sigma} ; \quad \sigma=\frac{P}{h . H}
$$

Where $\mathrm{P}$ is the applied axial force, and $\mathrm{h}$ and $\mathrm{H}$ are geometrical parameters of the specimen.

For stepped flat specimen with shoulder fillets:

$$
K_{t}=C_{1}+C_{2}\left(\frac{2 t}{H}\right)+C_{3}\left(\frac{2 t}{H}\right)^{2}+C_{4}\left(\frac{2 t}{H}\right)^{3}
$$

Where $\mathrm{t}$ and $\mathrm{H}$ are geometrical parameters of the specimen, and $C_{1}, C_{2}, C_{3}$ and $C_{4}$ are defined by (3):

$$
\begin{aligned}
& C_{1}=1,020+1,009 \sqrt{t / r}-0,048 t / r \\
& C_{2}=-0,065-0,165 \sqrt{t / r}-0,007 t / r \\
& C_{3}=-3,459+1,266 \sqrt{t / r}-0,016 t / r \\
& C_{4}=3,505-2,109 \sqrt{t / r}+0,069 t / r
\end{aligned}
$$

The topological optimization was performed with a given reduction of the mass of the studied specimens by $10 \%, 20 \%$ and $30 \%$, respectively.

The specimens after the topological optimization are presented in graphical form in Fig. 4 and Fig. 5.
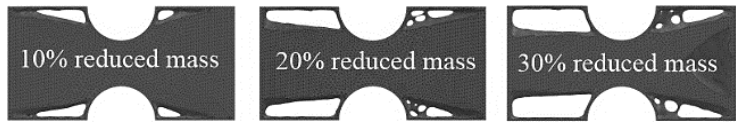

Fig. 4. Visualization of the rectangular plate after topological optimization.
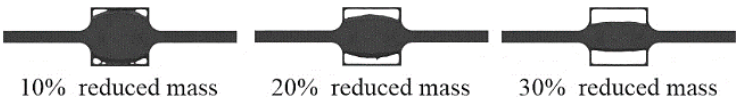

$10 \%$ reduced mass

$20 \%$ reduced mass

$30 \%$ reduced mass

Fig. 5. Visualization of the stepped flat specimen with shoulder fillets after topological optimization.

With the help of the additional specialized optimization module OptiSLang, the geometric parameters of the reduced material from the specimens have been identified, and the set target function is to minimize the stresses in the endangered areas.

\begin{tabular}{|c|c|c|c|}
\hline $\boldsymbol{r}$ & $\sigma$ nom $-10 \%$ & $\sigma$ nom $-20 \%$ & $\sigma$ nom $-30 \%$ \\
\hline$m \boldsymbol{m m}$ & $M P a$ & MPa & MPa \\
\hline 5 & 250,112 & 300,809 & 346,7 \\
\hline 10 & 272,703 & 296,655 & 388,727 \\
\hline 15 & 357,314 & 352,018 & 360,351 \\
\hline 20 & 568,111 & 568,423 & 575,822 \\
\hline
\end{tabular}

The stress values obtained after the optimization for the studied cases are presented in Table V and Table VI.

\begin{tabular}{|c|c|c|c|}
\hline \multicolumn{4}{|c|}{$\begin{array}{l}\text { Stress values obtained after the optimization for Stepped flat } \\
\text { specimen with shoulder fillets. }\end{array}$} \\
\hline$r$ & $\sigma$ nom $-10 \%$ & $\sigma$ nom $-20 \%$ & $\sigma$ nom $-30 \%$ \\
\hline $\mathbf{m m}$ & MPa & $\mathrm{MPa}$ & MPa \\
\hline 1,5 & 181,523 & 172,512 & 172,571 \\
\hline 2,5 & 165,308 & 161,639 & 159,412 \\
\hline 6 & 132,12 & 129,931 & 130,214 \\
\hline 10 & 119,005 & 118,727 & 121,054 \\
\hline
\end{tabular}

TABLE V.

Stress values obtained after the optimization for rectangular plate.

TABLE VI.

Fig. 6 and Fig. 7 shows the graphs of the stress concentration coefficient as a function of the geometric parameters of the studied specimens.

The analysis of the results shows that with the topological optimization of the rectangular plate, the reduction of the mass up to $20 \%$ can reduce the stresses in the endangered areas by more than $20 \%$.

In the topological optimization of stepped flat specimen with shoulder fillets, the stresses in the endangered areas in the considered cases decrease by more than $15 \%$. 


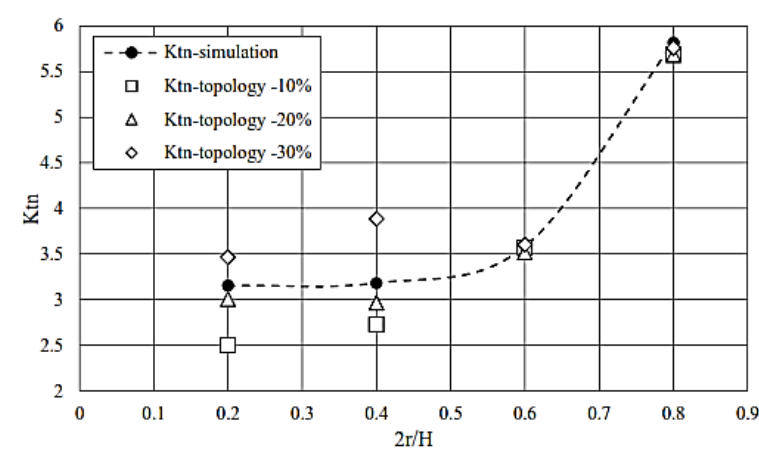

Fig. 6. Stress concentration coefficients after optimization for rectangular plate.

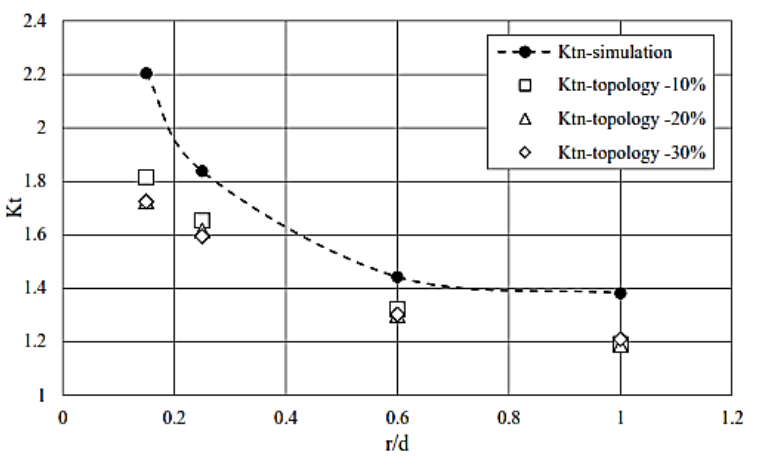

Fig. 7. Stress concentration coefficients after optimization for stepped flat specimen with shoulder fillets.

\section{CONCLUSIONS}

The object of the present work is to reduce the stress concentration in the tested specimens with the help of specialized software. The application of the modules "topological optimization" and "OptiSlang" in the ANSYS software proves to be a suitable method for realization of the set tasks and achievement of optimal solutions.
The results obtained from the simulations can be used as a basis for future experimental studies.

\section{ACKNOWLEDGEMENTS}

The authors would like to thank the Research and Development Sector at the Technical University of Sofia for the financial support.

\section{REFERENCES}

[1] A. Wankar, H. Mishra and J. Bayas, "Experimental Investigation of Reduction in SCF of Rectangular plate with central circular hole by Providing Relief Holes”, International Research Journal of Engineering and Technology (IRJET), Volume: 03 Issue: 061 June-2016.

[2] S. Sayyad and J. Shitole, "Exploration of the stress concentration in metallic plates with extraordinary cutout and bluntness", International Journal of Advanced Technology in Engineering and Science, Vol. No.5, Issue No. 05, May 2017.

[3] S. Karimi and J. Fesharaki, "Using Topology Optimization to Reduce Stress Concentration Factor in a Plate with a Hole", Journal of Stress Analysis Vol. 3, No. 2, Autumn - Winter 2018-19.

[4] L. Miegroet and P. Duysinx, "Stress Concentration Minimization of 2D filets using X-FEM and Level Set Description", Structural and Multidisciplinary Optimization volume 33, pages425438(2007).

[5] W. Waldman and M. Heller, "Shape optimisation of holes for multi-peak stress minimisation”, Australian Journal of Mechanical Engineering, Volume 3, $2006 \quad$ - Issue 1, https://doi.org/10.1080/14484846.2006.11464495

[6] D. Taylor, A. Kelly, M. Toso and L. Susrne, "The Variable Radius Notch: Two New Methods for Reducing Stress Concentration", Engineering Failure Analysis, Volume 18, Issue 3, April 2011, Pages 1009-1017, https://doi.org/10.1016/j.engfailanal.2010.12.012

[7] W. Pilkey, D. Pilkey and Z. Bi, "Peterson's Stress Concentration Factors, 4th Edition", ISBN: 978-1-119-53252-1, Wiley, January 2020 . 